\title{
Auditio; Revista Electrónica de Audiología
}

José Juan Barajas del Prat

Para citar este artículo:

Barajas del Prat J. (2001). Auditio; Revista Electrónica de Audiología. Auditio, 1(1), 1-2.

https://doi.org/10.51445/sja.auditio.vol1.2001.003

Enlace al artículo:

https://doi.org/10.51445/sja.auditio.vol1.2001.003

Historial:

Publicado (online): 15-09-2001 


\title{
Editorial
}

\section{Auditio: Revista Electrónica de Audiología}

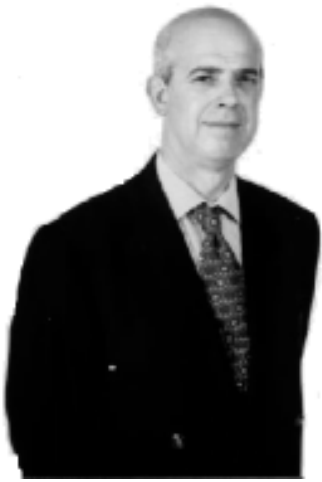

\author{
Dr. José Juan Barajas de Prat \\ Clínica Barajas
}

$\mathrm{L}$ as revistas científicas han sido el vehículo de comunicación de la ciencia desde el siglo XVII. Han servido para organizar el conocimiento en áreas de interés común y para el establecimiento de un nivel en la calidad de las publicaciones. Sin embargo y al mismo tiempo han segmentado la investigación en multitud de revistas y encarecido el acceso a las mismas. Por ejemplo, un tema de estudio como la esclerosis múltiple, puede encontrarse referenciada en más de 50 revistas distintas. Esto, para el profesional, significa una inversión en tiempo y coste en la adquisición de los artículos muchas veces desalentadoras. Las suscripciones han subido un $207 \%$ durante el período comprendido entre los años 1986 y 1999. Así mismo en ese mismo período ha habido un incremento del número de revista del $55 \%$. Esto ha llevado a las editoriales a una inflación en los precios no justificada en la mayoría de los casos. Así, por ejemplo, la suscripción anual en Brain Research cuesta aproximadamente $\$ 15000$.

El desarrollo de las revistas en formato electrónico ha sido vertiginoso. Las ventajas son obvias, la reducción de los costes de producción y de distribución, la posibilidad de interaccionar entre el lector y el autor, la amplia gama de presentación y diseño que permiten rapidez para difundir la información científica.

La mayoría de las publicaciones científicas tradicionales ofrecen hoy en la red su versión electrónica. Algunas incluso han llegado a desaparecer en su formato tradicional y hoy solo están disponibles electrónicamente. No cabe duda que estamos asistiendo a una revolución en la publicación científica en la que los próximos 5 años serán decisivos.

En Europa existen en lengua inglesa cinco revistas dedicadas a la audiología: Audiology, Neuro Otology and Audiology, British Audiology, Journal of Audiological Medicine y Scandinavian Audiology.
Las personas responsables de estas revistas se dan cuentan que mantener un alto nivel académico a la vez que reducir los costes exige plantearse la posibilidad de fusionar las publicaciones. En estos últimos meses nos consta que ha habido intentos por Scandinavian Audiology, Audiology y British Audiology de tratar de formar una sola publicación.

En español, las revistas de audiología son escasas y de aparición irregular. En general los artículos son de bajo nivel académico reflejando la poca tradición que tienen este disciplina como tal en el ámbito de nuestra comunidad hispano parlante. El portal que nosotros presentamos contiene, como no podía ser de otro manera, una parte fundamental dedicada a una revista electrónica en lengua española. Bajo esta perspectiva nace Auditio, publicación dedicada a la Audiología en formato electrónico. Nuestra revista asume un papel internacionalmente importante toda vez que trata con una disciplina extraordinariamente amplia y compleja. A decir verdad, la Audiología podría seguir muy bien la definición cervantina de la caballería andante: " una ciencia que encierra en sí todas o las más ciencias del mundo”. Efectivamente, el audiólogo debe saber anatomía para reconocer las distintas estructuras que constituyen el sistema auditivo, ha de ser fisiólogo porqué debe estar familiarizado con los mecanismos íntimos de la audición. Debe tener conocimientos de física, especialmente de acústica porqué tiene que entender los estímulos desencadenantes de la audición. Debe ser psicólogo para ayudar a sus pacientes en su rehabilitación. Tiene que conocer los distintos métodos de diagnóstico pues debe establecer la naturaleza de las distintas disfunciones audiológicas... en suma, juzguen usted " sí es ciencia mocosa lo que aprende el audiólogo que la estudia y profesa".

Nuestro propósito es que esta revista electrónica consiga los objetivos que las revistas impresas sobre audiología escritas en español no han podido 
conseguir hasta el momento: (1) distribución universal (2) bajos costes (3) aparición regular y (4) nivel científico aceptable. Que duda cabe que para que estos objetivos se puedan conseguir necesitamos la colaboración de todos. Sobre todo que perdamos la suspicacia y enviemos nuestras contribuciones más relevantes a estas revistas que ahora surgen en nuestra red. Que se sometan con gusto a los revisores internacionales del consejo editorial y sobre todo que se sientan reconocidos científicamente en nuestra revista. En nombre propio y del comité editorial le agradecemos su colaboración y le damos la más calurosa bienvenida a la Revista electrónica de Audiología: Auditio.

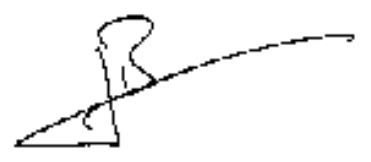

Dr. José Juan Barajas de Prat

E-mail: barajas@clinicabarajas.com 